\title{
Response to commentary on "the middle fossa approach with self-drilling screws: a novel technique for BONEBRIDGE implantation"
}

\author{
Peng You', Lauren H. Siegel ${ }^{1}$, Zahra Kassam², Matthew Hebb³ ${ }^{3}$ Lorne Parnes ${ }^{1 \dagger}$, Hanif Ladak $^{4 \dagger}$ and
}

Sumit Kishore Agrawal ${ }^{1 *+}$ (iD

\begin{abstract}
The aim of this letter is to respond to a commentary on a published article on the middle fossa approach to BONEBRIDGE implantation with self-drilling screws published by the senior authors.

Keywords: Bone conduction implant, BONEBRIDGE, Middle fossa approach, Conductive hearing loss, Surgical technique, Implants
\end{abstract}

\section{Dear Dr. Carnevale,}

We appreciate your support of the middle fossa approach and your feedback on this paper. The senior author (S.K.A.) developed the middle fossa technique with self-drilling screws in 2012 to treat patients with mastoid cavities, and the first patient was implanted following this approach in April, 2013 at the London Health Sciences Centre [1, 2]. This particular technique was previously published $[3,4]$, and the current series examines the long-term results (40 patients, up to 71 months follow-up).

It is exciting that your group subsequently adopted a similar surgical technique (14 patients, up to 45 months follow-up). Furthermore, it is reassuring that surgical and audiologic outcomes were similar between centres, regardless of whether self-drilling or self-tapping screws were used. We apologize that we were unable to cite your results within the current paper. Unfortunately, our manuscript was completed for submission prior to the publication of your paper in April, 2019.

\footnotetext{
* Correspondence: sumit.agrawal@lhsc.on.ca

${ }^{\dagger}$ Lorne Parnes, Hanif Ladak and Sumit Kishore Agrawal are co-senior authors ${ }^{1}$ Department of Otolaryngology-Head and Neck Surgery, London Health Science Centre, Schulich School of Medicine \& Dentistry, Western University, Room B1-333, London Health Sciences Centre - University Hospital 339 Windermere Road, London, Ontario N6A 5A5, Canada

Full list of author information is available at the end of the article
}

To the best of our knowledge, the use of a neurosurgical perforator or trocar for the BONEBRIDGE was first published by Barbara et al. in 2013 [5], albeit in the retrosigmoid approach. As mentioned in our paper, we also used the neurosurgical perforator in our first few middle fossa patients. Although use of the perforator was quick to create the initial craniotomy $(14 \mathrm{~mm}$ outer drill and $11 \mathrm{~mm}$ inner drill), expansion of the craniotomy to $16 \mathrm{~mm}$ to fit the BONEBRIDGE took additional surgical time. In your paper (and supplementary video), initial craniotomoy using the perforator took $14 \mathrm{~s}$, however the total craniotomy time including enlargement with the Kerrison rongeur was not described.

Neurosurgical perforators are associated with complications [6, 7], and have significantly higher costs than regular otologic drills [8]. Use of otologic drills to create the craniotomy is a safe and efficient alternative, and neurotologists comfortable with the middle fossa approach for acoustic neuromas should be familiar with this method. Therefore, the senior authors (L.S.P. and S.K.A.) opted to exclusively switch to otologic drills, and no adverse events or significant increases in operative time were noted.

(c) The Author(s). 2019 Open Access This article is distributed under the terms of the Creative Commons Attribution 4.0 International License (http://creativecommons.org/licenses/by/4.0/), which permits unrestricted use, distribution, and reproduction in any medium, provided you give appropriate credit to the original author(s) and the source, provide a link to the Creative Commons license, and indicate if changes were made. The Creative Commons Public Domain Dedication waiver (http://creativecommons.org/publicdomain/zero/1.0/) applies to the data made available in this article, unless otherwise stated. 


\section{Acknowledgements}

Not applicable

\section{Authors' contributions}

All authors contributed equally to this response letter. All authors read and approved the final manuscript.

\section{Funding}

There were no sources of funding.

\section{Availability of data and materials}

Not applicable

\section{Ethics approval and consent to participate}

Not applicable

\section{Consent for publication}

Not applicable

\section{Competing interests}

LP is on the surgical advisory board for Med-El. The other authors declare that they have no competing interests.

\section{Author details}

'Department of Otolaryngology-Head and Neck Surgery, London Health Science Centre, Schulich School of Medicine \& Dentistry, Western University, Room B1-333, London Health Sciences Centre - University Hospital 339 Windermere Road, London, Ontario N6A 5A5, Canada. ${ }^{2}$ Department of Medical Imaging, St. Joseph's Health Care London, Schulich School of Medicine \& Dentistry, Western University, London, Canada. ${ }^{3}$ Department of Clinical Neurological Sciences, London Health Science Centre, Schulich School of Medicine \& Dentistry, Western University, London, Canada. ${ }^{4}$ Department of Medical Biophysics, Schulich School of Medicine \& Dentistry, Western University, London, Canada.

Received: 11 September 2019 Accepted: 21 September 2019 Published online: 05 November 2019

\section{References}

1. Bone implant gives new hope to hearing impaired. CTV News. 2013. https:// www.ctvnews.ca/sci-tech/bone-implant-gives-new-hope-to-hearingimpaired-1.1277726. Accessed 1 Sept 2019.

2. LHSC first in North America to perform BONEBRIDGE bone conduction implant. London Health Sciences Centre. 2013. https:/www.l.hsc.on.ca/ news/lhsc-first-in-north-america-to-perform-bonebridge-bone-conductionimplant. Accessed 1 Sept 2019.

3. Zernotti ME, Sarasty AB. Active bone conduction prosthesis: BonebridgeTM. Int Arch Otorhinolaryngol. 2014;19(4):343-8.

4. Manoj MP, Agrawal S. Middle Fossa approach to bone bridge surgery: presenting author: Manoj M P. J Laryngol Otol. 2016. https://doi.org/10. 1017/S0022215116006149.

5. Barbara M, Perotti M, Gioia B, Volpini L, Monini S. Transcutaneous boneconduction hearing device: Audiological and surgical aspects in a first series of patients with mixed hearing loss. Acta Otolaryngol. 2013;133(10):1058-64

6. Vogel TW, Dlouhy BJ, Howard MA. Don't take the plunge: avoiding adverse events with cranial perforators. J Neurosurg JNS. 2011. https://doi.org/10. 3171/2011.3.JNS101310.

7. Caird JD, Choudhari KA. 'Plunging' during burr hole craniostomy: a persistent problem amongst neurosurgeons in Britain and Ireland. $\mathrm{Br}$ Neurosurg. 2003;17(6):509-12.

8. Menovsky T, Kamerling N, Plazier M, Maas Al. Letter to the editor: complications with cranial perforators. J Neurosurg JNS. 2014. https://doi. org/10.3171/2012.3.JNS112168.

\section{Publisher's Note}

Springer Nature remains neutral with regard to jurisdictional claims in published maps and institutional affiliations. 